\title{
Cug2 is essential for normal mitotic control and CNS development in zebrafish
}

\author{
Hyun-Taek Kim, Ju-Hoon So', Seung-Hyun Jung ${ }^{1}$, Dae-Gwon Ahn', Wansoo Koh², Nam-Soon Kim³, \\ Soo-Hyun Kim ${ }^{4}$ Soojin Lee ${ }^{2^{*}}$ and Cheol-Hee Kim ${ }^{1 *}$
}

\begin{abstract}
Background: We recently identified a novel oncogene, Cancer-upregulated gene 2 (CUG2), which is essential for kinetochore formation and promotes tumorigenesis in mammalian cells. However, the in vivo function of CUG2 has not been studied in animal models.

Results: To study the function of CUG2 in vivo, we isolated a zebrafish homologue that is expressed specifically in the proliferating cells of the central nervous system (CNS). Morpholino-mediated knockdown of cug2 resulted in apoptosis throughout the CNS and the development of neurodegenerative phenotypes. In addition, cug2-deficient embryos contained mitotically arrested cells displaying abnormal spindle formation and chromosome misalignment in the neural plate.

Conclusions: Therefore, our findings suggest that Cug2 is required for normal mitosis during early neurogenesis and has functions in neuronal cell maintenance, thus demonstrating that the cug2 deficient embryos may provide a model system for human neurodegenerative disorders.
\end{abstract}

\section{Background}

Cancer-upregulated gene 2 (CUG2) is known to be differentially expressed in multiple human cancer tissues including the ovary, liver, lung, intestines and pancreas [1]. Mammalian cells overexpressing CUG2 showed hallmarks of neoplasmic transformation in vitro, such as increased cell proliferation, migration, invasion, anchorage-independent growth and tumor formation in nude mice, similar to the effects of the H-ras oncogene [1].

Recently, CUG2 was shown to interact with CENP-T and CENP-A, essential components of the nucleosome complex located at the centromere, and was hence named centromere protein W (CENP-W) [2,3]. The centromere is involved in sister chromatid cohesion and the attachment of spindle microtubules, and is thus responsible for accurate chromosome segregation during mitotic and meiotic cell division [4]. CENP-A, a histone H3-like core protein, is required for the recruitment of

\footnotetext{
* Correspondence: leesoojin@cnu.ac.kr; zebrakim@cnu.ac.kr

'Department of Biology, Chungnam National University, Daejeon, South

Korea

${ }^{2}$ Department of Microbiology, Chungnam National University, Daejeon,

South Korea

Full list of author information is available at the end of the article
}

many constitutive centromere components as well as transient kinetochore components $[5,6]$. We and others have reported that CUG2/CENP-W forms a DNA-binding complex together with the CENP-T and CENP-A as part of the centromere chromatin structure $[2,3]$. SiRNA-mediated knockdown of CUG2/CENP-W in HeLa cells caused defective mitosis characterized by multipolar spindle formation as well as chromosomal misalignment and hypercondensation, resulting in mitotic arrest $[2,3]$. However, the in vivo function of CUG2 has not been studied in animal models.

To elucidate the endogenous function of CUG2 in vivo, we investigated the expression patterns and potential roles of cug2 in zebrafish during early embryogenesis. Our results indicate that Cug2 is essential for normal mitosis and CNS development, and that loss of Cug2 function lead to neurodegenerative phenotypes.

\section{Results}

Identification of the zebrafish cug2 homologue

A zebrafish cug2 homologue was isolated from a $24 \mathrm{hpf}$ embryonic cDNA library. The zebrafish cug2 (Genbank: XM_683789) is composed of 3 exons encoding 75 amino acids. The nuclear localization signal in the $N$ -

\section{() Biomed Central}


terminus is highly conserved among CUG2 homologues. Clustal $\times$ analysis indicates that the zebrafish Cug2 amino acid sequence shows $58 \%$ and $62 \%$ similarity to human (Genbank: AY902475) and mouse (Genbank: XP_488549), respectively (Figure 1A). To more precisely confirm the evolutionary conservation of CUG2, we investigated the distribution of genes located adjacent to the CUG2 locus on chromosomes in zebrafish and human using the online program Synteny Database [7]. Two genes, TRMT11 and RSPO3, were located close to each other on human chromosome 6 near CUG2, and their zebrafish orthologues were located in the vicinity of cug 2 on chromosome 16 (Figure 1B), indicating that zebrafish cug2 was an orthologue of human CUG2. The predicted fish cug2 sequence in the NCBI database (Genbank: XM_704089) suggests an isoform with alternative splicing of exon 3, and no additional isoforms were detected by RT-PCR. In addition, no evidence of a second orthologue was found.

To determine the temporal and spatial expression patterns of the cug2 gene during zebrafish development, stage- and tissue-specific RT-PCR and in situ hybridization were performed, revealing that zebrafish cug2 transcripts have both maternal and zygotic expression patterns (Figure 2A). cug2 mRNA was detectable at variable levels throughout the early embryonic stages (1-48

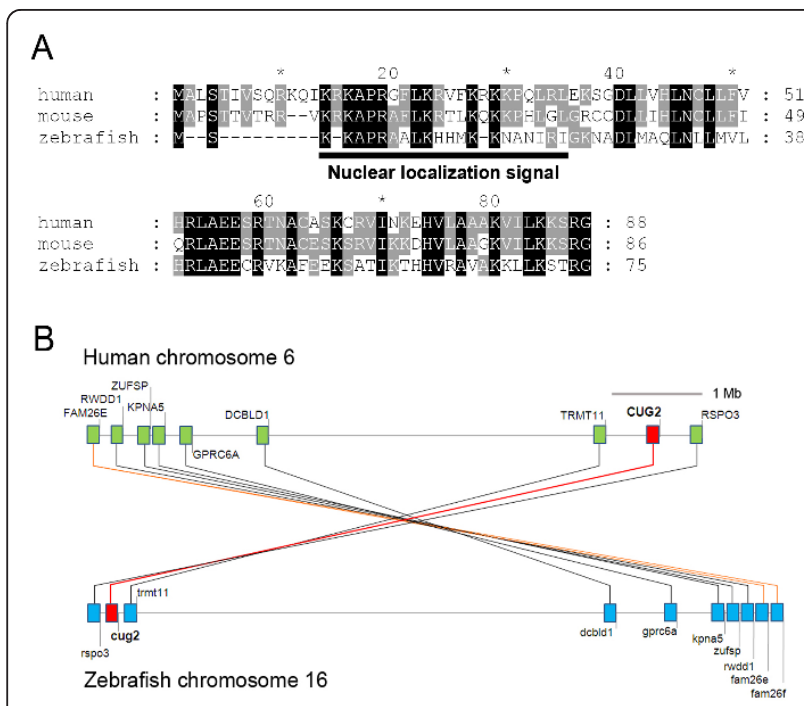

Figure 1 Amino acid comparison and synteny analysis of CUG2 gene. A. Clustal $X$ alignment of CUG2 amino acid sequences of vertebrate homologues, with identical residues marked in black. B. Synteny between cug2 on zebrafish chromosome 16 and CUG2 on human chromosome 6. Using Synteny Database, synteny in the vicinity of cug2 gene were analyzed using zebrafish (Zv8) as the source genome and human (GRCH37) as the outgroup. The approximate position of cug2 is marked in red. Orthologue pairs of genes are connected by lines. Non-paired genes are not shown. The synteny occurs between the segments of zebrafish chromosome 16 and human chromosome 6 that contain the CUG2 gene. hpf; Figure 2A) and in selected tissues in the adult (Figure 2B). Whole-mount in situ hybridization showed that cug2 transcripts were ubiquitously expressed throughout the embryonic body from cleavage to the early somite stage (Figure 2C-F). At 24-36 hpf, cug2 expression was specifically detected in the lateral line primordium, gut, and CNS including the telencephalon, midbrain, midbrain-hindbrain boundary, hindbrain, and spinal cord (Figure 2G, H). At $48 \mathrm{hpf}$, the cug2-expressing region overlapped with a proliferating cell marker, pcna-expressing region, such as those in the ciliary marginal zone in the eyes, tectum, midbrain-hindbrain boundary, neural crest cells, pectoral fin buds, and gut (Figure 2I, J, L). However, the expression domains of cug2 were not overlapped with that of $h u C$, a differentiating neuronal marker (Figure $2 \mathrm{~K}$ ). These restricted and yet overlapping expression patterns indicate that cug2 is expressed mainly in the proliferating cell population of the CNS during early embryonic development in zebrafish.

\section{Knock-down analysis of cug2 in zebrafish embryos}

To investigate the endogenous roles of cug2, knockdown analysis was performed using an antisense oligonucleotide morpholino (MO). The cug2 MO was designed to target the splicing donor site of exon 1 , resulting in an aberrant transcript with a premature stop codon at residue 31 (Figure 3A). RT-PCR confirmed that injection of the cug2 MO into zebrafish embryos successfully blocked the splicing of $\operatorname{cug} 2$ transcripts (Figure 3A, B). Also, we designed other MO to target the translation start site (Figure 3A) and then confirmed that the MO specifically inhibits the translation of cug2-GFP containing its targeting region (Additional File 1: Figure. S1C, D). After $3 \mathrm{dpf}$, cug2 MOinjected embryos consistently displayed a range of characteristic phenotypes including flat head, small eyes, pinched midbrain-hindbrain boundary, thin yolk extension, and curved body (Figure 3C, D, Additional File 1: Figure. S1A, B, E, F). This phenotype was rescued by co-injection of wild-type cug2 mRNA, but not by injection of $p 53 \mathrm{MO}$ (Figure 3E, F), confirming that the observed phenotype is specific to the effect of $c u g 2$ knockdown and not due to $p 53$-dependent cell death, a typical off-target effect of MO [8].

To further determine whether the phenotypes observed in cug2 morphants were caused by apoptotic cell death, cug2 MO-injected embryos were analyzed by acridine orange staining. Acridine orange-positive cells were clearly and broadly detected throughout the bodies of $c u g 2$ morphants at $28 \mathrm{hpf}$, particularly in the CNS including the eye, brain, and spinal cord (Figure 3G, H). These data suggest that the phenotypes induced by morpholino knockdown of cug 2 result from induction of apoptosis during early embryogenesis. 


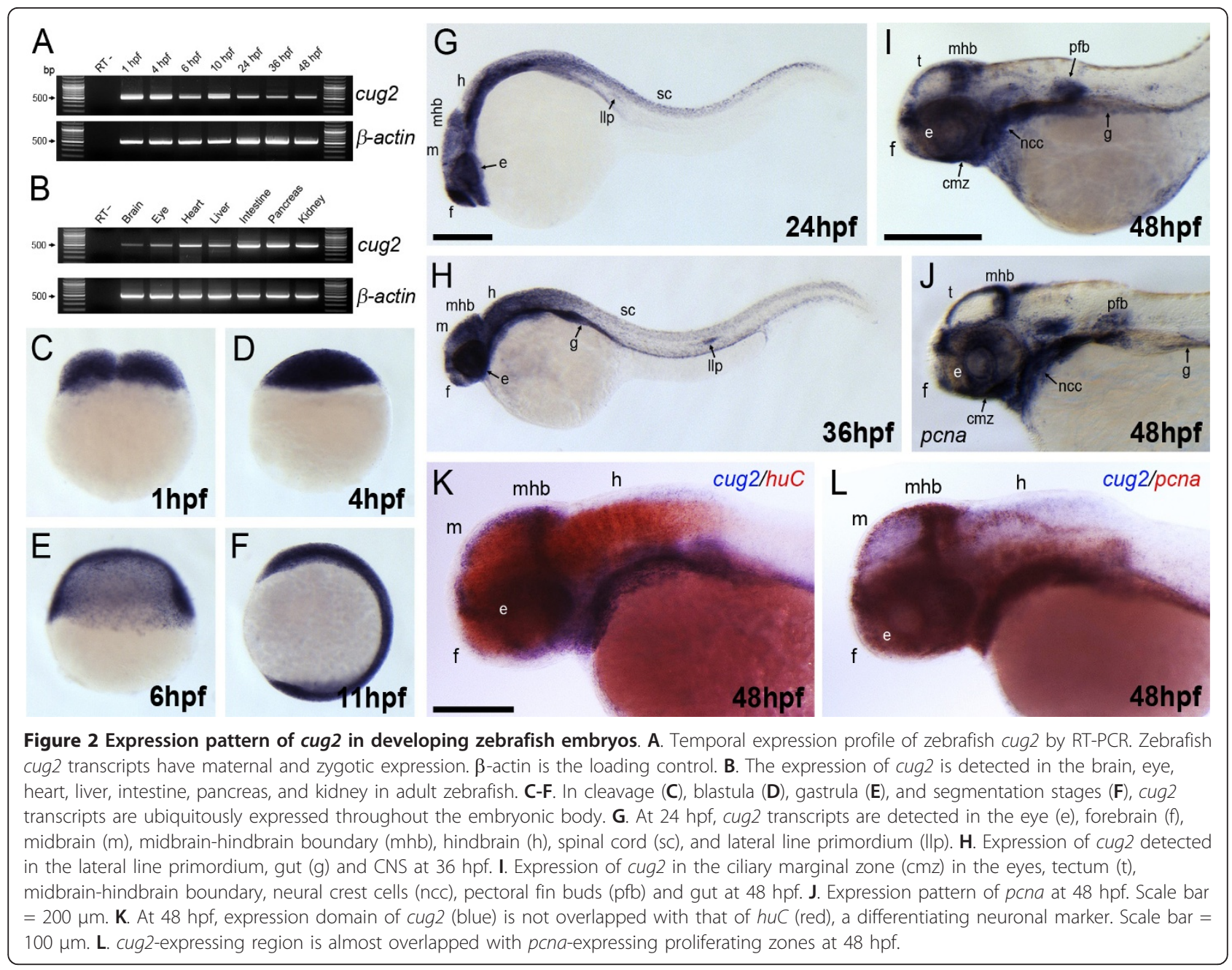

\section{cug2 deficiency causes neurodegeneration}

The phenotypes of cug2 MO-injected embryos are remarkably similar to previously reported neural degenerative mutants in zebrafish, such as psm, terf 2 , and tub [9-12]. Furthermore, the cug 2 morphants exhibited extensive apoptotic cell death in the CNS (Figure 3G, $\mathrm{H})$. Therefore, we utilized the $\mathrm{Tg}[\mathrm{huC}$ :GFP] transgenic line that expresses neuron-specific GFP under the control of the $h u C$ promoter [13] to determine whether cug2 knock-down causes neuronal degeneration. Microinjection of cug $2 \mathrm{MO}$ into $\mathrm{Tg}[\mathrm{huC}$ :GFP] transgenic embryos caused a reduction in the expression of GFPpositive neurons in the CNS, particularly in the nucleus of the medial longitudinal fasciculus (nMLF) and neurons of the hindbrain rhombomere at $26 \mathrm{hpf}$ (Figure 4A, B). Moreover, the number of $h u C$-positive differentiating neurons was dramatically decreased in cug2 morphants (Additional File 2: Figure. S2G, G'). Next, embryos were immunostained with anti-acetylated $\alpha$-tubulin to investigate whether cug2 morphants display architectural defects of the axonal scaffold in the brain. As expected, the axonal scaffolds in the anterior commissure (ac), olfactory nerve (ofn), and nMLF were significantly deteriorated, as evidenced by significantly weaker acetylated $\alpha$-tubulin staining compared to control. Particularly, organization of the commissural axons in the rhombomere segments was severely disturbed in cug $2 \mathrm{MO}-$ injected embryos (Figure 4C, D). In addition, reduced arborization was evident in neurons such as the spinal cord Rohon-Beard (RB) sensory neurons (Figure 4E, F).

To further define the neurodegenerative phenotype at the histological level, hematoxylin-eosin (H\&E) staining was performed on serial paraffin sections of the brain, retina, and spinal cord at $3 \mathrm{dpf}$. Like other vertebrates, the zebrafish retina consists of six layers (ganglion cell, inner plexiform, inner nuclear, outer plexiform, outer nuclear, and pigment cell layers) and contains six types of neurons and one type of glial cell [14]. At $3 \mathrm{dpf}$, cug2 morphants showed severe disruption in the layer formation and pyknotic cells in the retina compared to 


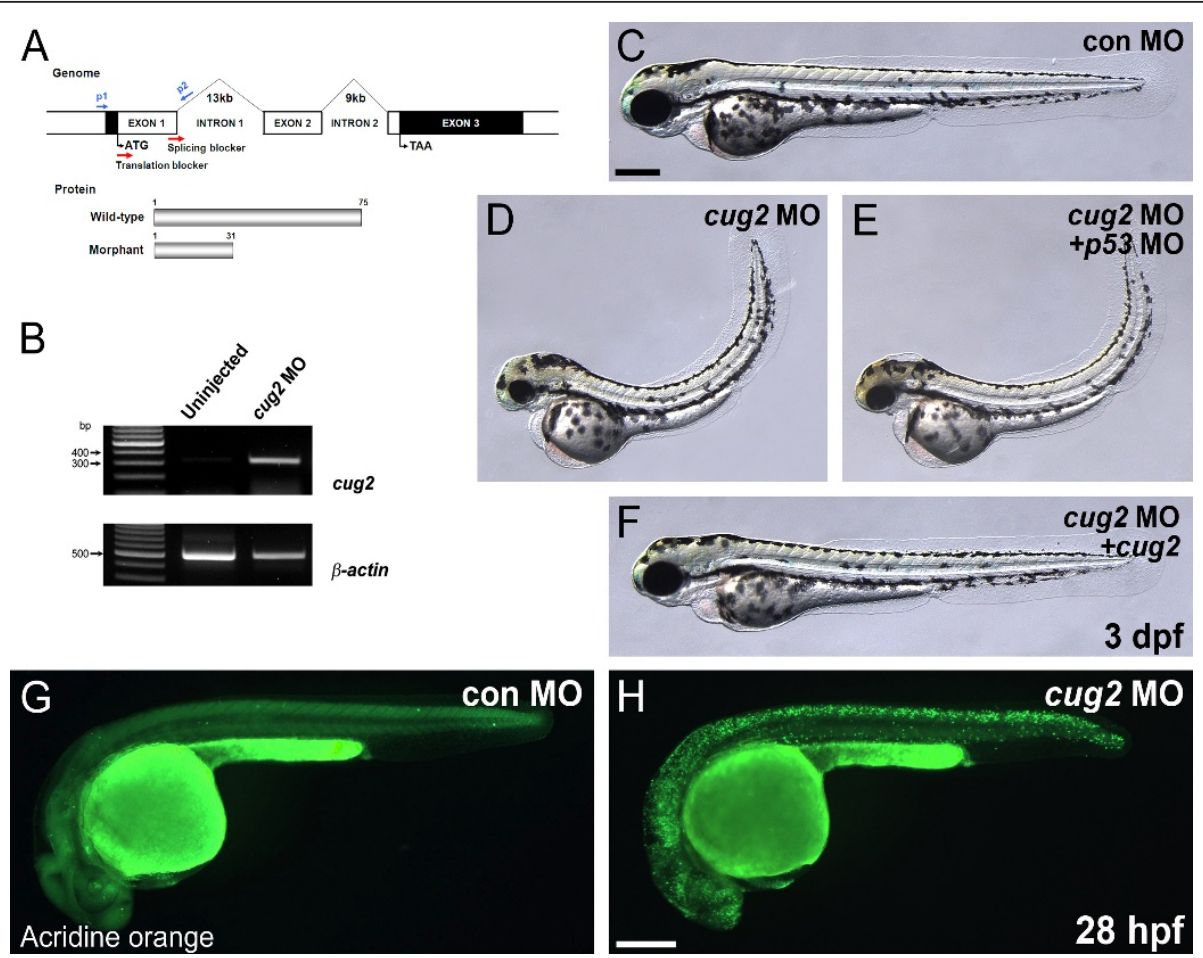

Figure 3 Knock-down analysis of cug2 by morpholinos. A. Genomic structure and MO targeting region (red arrow) of the zebrafish cug2 gene. B. Confirmation of the splice-blocking effect of MO by RT-PCR using p1-p2 primers (in A). Aberrant transcripts were amplified only in cug2 MO-injected embryos. $\beta$-actin is the loading control. C-F. In contrast to the control MO (C), cug2 MO-injected embryos (D) display

neurodegenerative phenotypes including a flat head, small eyes, pinched midbrain-hindbrain boundary, thin yolk extension, and curved-up body at $3 \mathrm{dpf}$. Injection of p53 MO (E) did not affect these phenotypes in cug2 morphants, while co-injection of wild-type cug2 mRNA (F) rescued it at $3 \mathrm{dpf}$. G, H. Detection of cell death in CNS by acridine orange staining of cug2 MO- $(\mathbf{H})$ and control MO-injected (G) embryos at 28 hpf. Scale bars $=250 \mu \mathrm{m}$

control embryos (Figure 4G, H). Moreover, in the spinal cord, both the number of cells in the neural tube and the size of the neural tube were dramatically decreased in cug2 MO-injected embryos (Figure 4I, J). Interestingly, cug2 deficiency appeared to affect specific subpopulations of the developing neurons; during primary neurogenesis $(3 \mathrm{ss})$ in the neural plate, $n g n 1$ and deltapositive neuronal precursors were slightly increased by cug2 knockdown, while the huC/elavl3-positive differentiating neurons were decreased (Additional File 2: Figure. S2A-C, H). In contrast, during secondary neurogenesis (20 ss), both neuronal precursors and differentiating neurons were affected (Additional File 2: Figure. S2D-F'). These results indicate that cug2 may function in normal differentiation and/or maintenance of neurons rather than early neuronal precursor determination.

\section{cug2 morphants exhibit mitotic defects}

CUG2 was previously identified as a component of the constitutive centromere-associated network (CCAN) and abnormal mitotic events such as multipolar spindle formation and chromosome misalignment were observed in CUG2-depleted mammalian cells [2,3]. We first examined whether Cug2 localizes to cell's nucleus in zebrafish embryos, using GFP-tagged Cug2 protein. The behavior of Cug2-GFP is reminiscent of the behavior of the chromosomes during various stages of cell cycle in living zebrafish embryo (Additional File 3: Figure. S3AC), thus suggesting that Cug2 is involved in mitosis in zebrafish. To investigate whether cug2-deficient embryos exhibit any defects in mitosis, embryos were doublestained with anti- $\alpha$-tubulin antibody and Hoechst 33342 dye at the neural plate stage to visualize the mitotic spindles and metaphase chromosomes, respectively. In cug2 MO-injected embryos, $\alpha$-tubulin-positive spindles were short and disorganized compared to the control embryos (Figure 5A-D"). In addition, cug2-deficient embryos exhibited varying degrees of disorganized metaphasic chromosome alignment (Figure 5'A-D').

Next, cug2 morphants were examined to determine whether there were any changes in the number of metaphase cells. Immunostaining of the embryos with an antibody against phosphorylated histone $\mathrm{H} 3$ (pH3), a mitotic marker [15], revealed that cug 2 morphants experienced a significant increase in the number of 

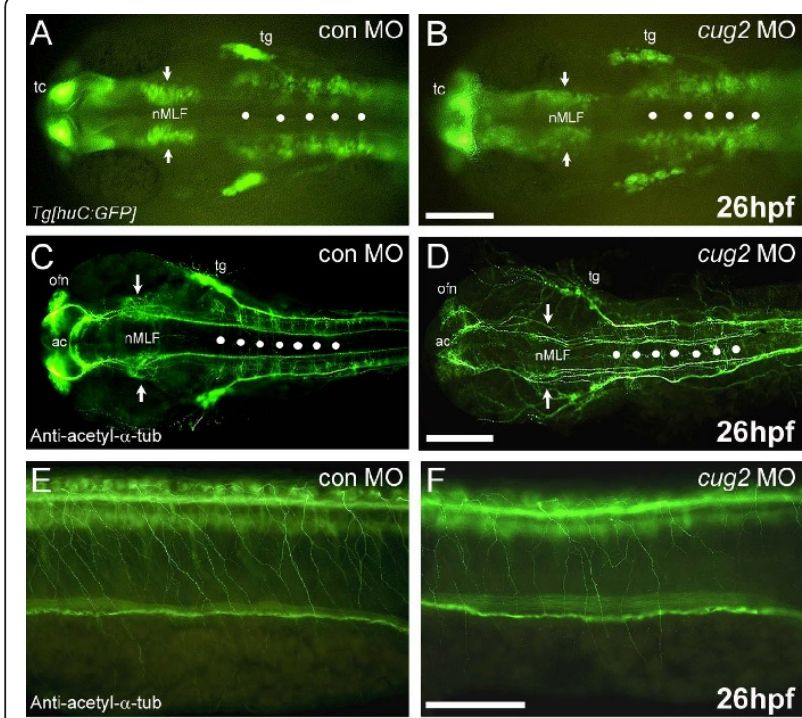

G
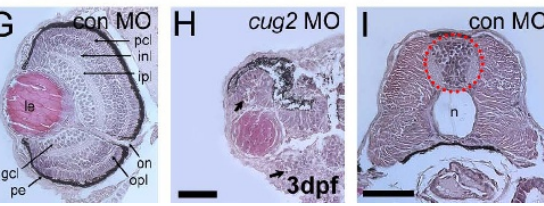

cug2 $\mathrm{MO}$

Figure 4 cug2 deficiency causes neurodegeneration in developing embryos. A, B. In huC:GFP transgenic embryos, injection of cug2 $\mathrm{MO}$ (B) causes a reduction in the number of neurons in the nucleus of the medial longitudinal fasciculus (nMLF, arrows) and the rhombomere (white spots) compared to control

MO (A). Scale bar $=200 \mu \mathrm{m}$. C, D. Anti-acetylated $\alpha$-tubulin staining of the brain of control (C) and cug2 morphants (D). cug2 deficiency causes axonal scaffolding defects in the anterior commissure (ac), olfactory nerve (ofn), nMLF (arrows), and hindbrain commissure (white spots) at 26 hpf. Scale bar $=200 \mu \mathrm{m}$. E, F. Anti-acetylated $\alpha$ tubulin staining of the spinal cord of cug2 morphants (F) at 26 hpf shows reduced arborization in Rohon-Beard (RB) sensory neurons compared to control (E). Scale bar $=100 \mu \mathrm{m}$. G-J. Histological sections of control $(\mathbf{G}, \mathbf{I})$ and cug2 $\mathrm{MO}(\mathbf{H}, \mathbf{J})$-injected embryos at 3 dpf. cug2 morphants exhibit severely disrupted retina layer formation $(\mathbf{H})$ and a much smaller neural tube that contains fewer cells (J). gcl, ganglion cell layer; inl, inner nuclear layer; ipl, inner plexiform layer; le, lens; n, notochord; on, optic nerve; opl, outer plexiform layer; pcl, photoreceptor cell layer; pe, pigmented epithelium. Scale bars $=50 \mu \mathrm{m}$.

pH3-positive cells in the spinal cord at 24 hpf (Figure $5 \mathrm{E}, \mathrm{F}, \mathrm{I})$. The increased number of $\mathrm{pH} 3$-positive cells in the cug 2 morphants likely represents an increase in mitotic arrest, rather than enhanced cell proliferation, since there was no significant difference in BrdU incorporation between the control and cug2 morphants (Figure $5 \mathrm{G}, \mathrm{H}, \mathrm{J})$.

Combined, these results support the notion that loss of cug2 function causes defective mitosis, leading to mitotic arrest during early neurogenesis. We speculate that zebrafish cug2 is required for the normal function of the mitotic spindle and chromosome arrangement at the metaphase plate, consistent with the results from mammalian cell lines.

\section{Discussion}

Here, we report that a zebrafish orthologue of a recently identified human centromeric protein CUG2/CENP-W is crucially important for normal mitosis and neurogenesis during early CNS development. Knockdown of cug2 expression in developing embryos caused a dramatic increase in the number of mitotically arrested cells exhibiting abnormal spindle formation and chromosome misalignment (Figure 5), as well as extensive apoptotic cell death associated with neurodegenerative phenotypes (Figures 3 \&4).

We and others have previously shown that CUG2/ CENP-W is a component of CCAN and participates in the formation of the DNA-binding complex together with CENP-A, CENP-C, and CENP-T at the kinetochore in mammalian cells $[2,3,6]$. Our current study further extends this notion and supports an essential role for zebrafish cug2 in kinetochore assembly, defects of which may elicit the checkpoint control mechanism and result in mitotic arrest. The genomic instability caused by the loss of cug 2 affects cell viability, as evidenced by extensive apoptosis, leading to neurodegeneration early in CNS development in zebrafish. A number of studies in mice have shown that null mutations of the genes encoding most of the centromere proteins cause defective or arrested mitosis, and result in a degenerative phenotype and embryonic lethality [16-18]. In addition, genes encoding other zebrafish centromeric proteins, such as cenpa/seph, cenpl and cenpn, are mainly expressed in the proliferating regions during embryogenesis. Insertional mutation of these genes (seph ${ }^{\text {hi2737Tg, }}$ cenpl $^{\text {hi3634Tg }}$, and cenpn ${ }^{\text {hi3505Tg }}$ ) results in neurodegenerative phenotypes [19] similar to those of the $c u g 2$ morphants described in our study (Figure 3D).

Errors in chromosomal segregation due to compromised mitotic checkpoint control leads to aneuploidy, as often observed in transformed cell lines and human tumors. It has been postulated that common molecular pathways may be involved in both oncogenesis and neurodegeneration, and that genetic alterations of these pathways can lead to either carcinogenesis or neurodegeneration depending on the cellular context [20]. Considering the fundamental importance of genome stability in development, differentiation, growth and homeostasis of an organism, the data presented here support the critical role of CUG2 in both cancer and neurodegenerative diseases.

\section{Conclusions}

In conclusion, this study suggests that Cug2 is required for normal mitosis during early neurogenesis and has 


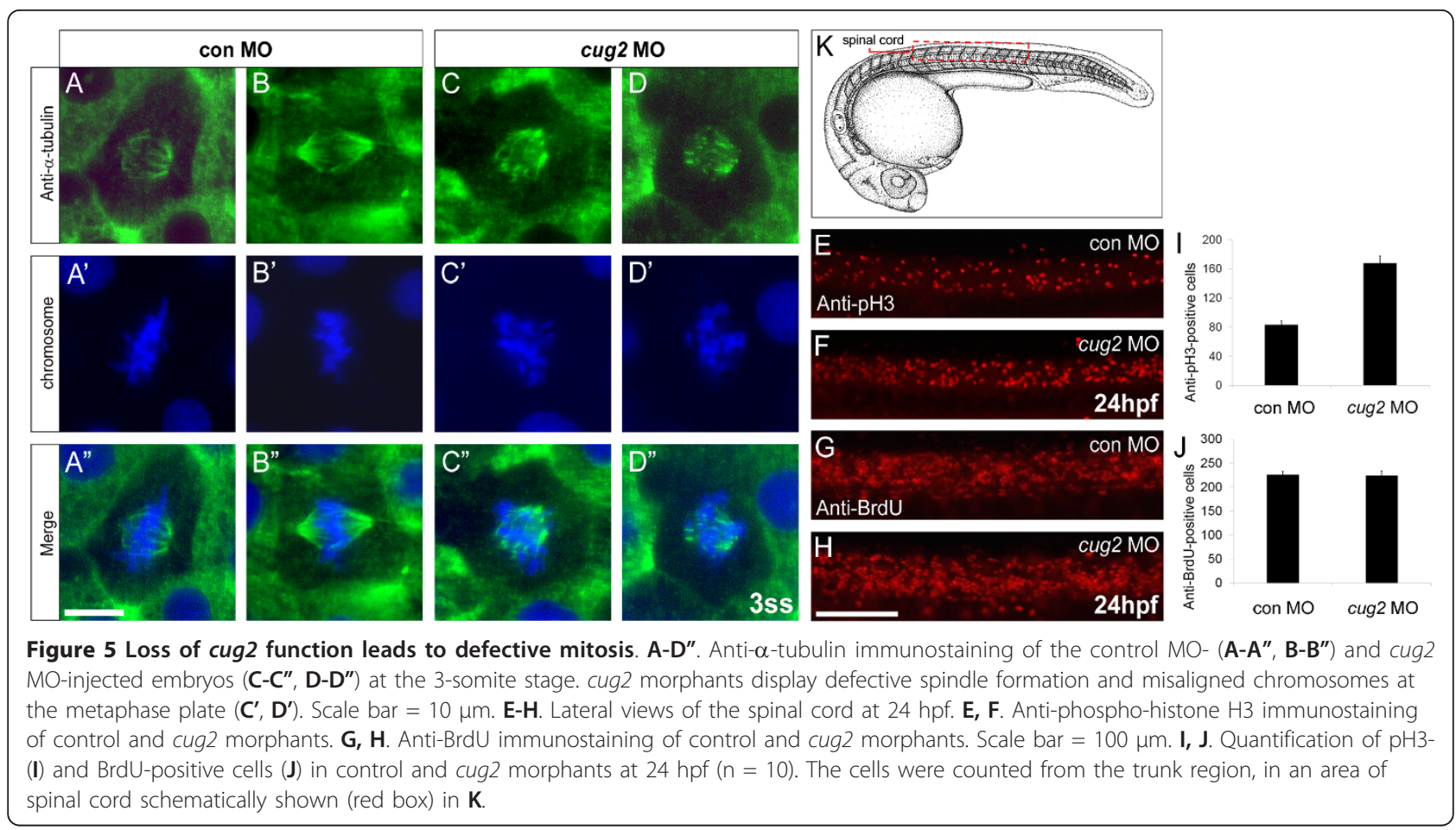

functions in neuronal cell maintenance, thus demonstrating that the cug2 deficient embryos may provide a model system for human neurodegenerative disorders.

\section{Methods}

\section{Fish stocks and maintenance}

Adult fish were maintained at $28.5^{\circ} \mathrm{C}$ on a 14-hr light/ 10-hr dark cycle. $T g[h u C: G F P]$ was used in knock-down experiments [13]. Embryonic stages were determined by the postfertilization hour and microscopic observation. Some of the embryos were treated with phenylthiocarbamide (1-phenyl-2-thiourea, PTU; Sigma) to suppress melanin synthesis. Animal work was approved by the internal animal ethics committee at Chungnam National University (No. 2010-3-6).

\section{Cloning of the zebrafish cug2 homologue}

To isolate the zebrafish cug2 gene, a cDNA fragment from a 24 hpf zebrafish cDNA was amplified by RTPCR based on the NCBI sequence (Genbank: XM_683789). The 519 bp PCR products were cloned into the pGEM-T easy vector (Promega, USA) and then subcloned into the EcoR I site in a pCS2+ expression vector. To construct the cug2-GFP fusion reporter into pCS2+ GFP expression vector, the specific enzymelinked primers were designed for PCR amplification. PCR products were subcloned into the NcoI site in pCS2+GFP vector.
Whole-mount in situ hybridization, immunostaining and apoptosis detection

To synthesis the RNA probe, a pGEM-T easy vector harboring the cug2 gene was linearized with Sal I and antisense cug2 RNA was transcribed in vitro using T7 RNA polymerase and digoxigenin or fluorescein-labeled UTP. The full-length cDNA of pcna (Genbank: AF140608) was amplified from a $24 \mathrm{hpf}$ cDNA and cloned into a pGEM T-easy vector. Antisense digoxigenin-labeled RNA probes for $n g n 1$ [21], huC/elavl3 [22], deltaA [23], and pcna were produced using a digoxigenin-RNA labelling Kit (Roche, Germany) according to the manufacturer's instructions. Wholemount in situ hybridization was performed as previously described [24]. Whole-mount immunostaining was carried out as described previously [24] using anti- $\alpha$-tubulin, anti-acetylated $\alpha$-tubulin, anti-BrdU (all from Sigma), and anti-phospho-histone H3 Ser10 (Cell Signaling) antibodies. For BrdU incorporation, dechorionated embryos were incubated with $10 \mathrm{mM} \mathrm{BrdU}$ in $15 \%$ DMSO/egg water $(60 \mu \mathrm{g} / \mathrm{ml}$ sea salts (Sigma) in distilled water) for 20 minutes at $4^{\circ} \mathrm{C}$ and then for exactly $5 \mathrm{~min}$ utes at $28.5^{\circ} \mathrm{C}$, followed by $4 \%$ paraformaldehyde fixation overnight at $4^{\circ} \mathrm{C}$ and dehydration in methanol at $-20^{\circ} \mathrm{C}$. To stain nuclei, the embryos were fixed in $4 \%$ paraformaldehyde, stained for 10 minutes with Hoechst 33342 (Sigma) and washed in PBS. For detection of apoptotic cells, embryos were placed in $10 \mu \mathrm{g} / \mathrm{ml}$ acridine orange 
(Sigma) diluted in egg water for 30 minutes and then washed in egg water.

\section{Paraffin sectioning and H\&E staining}

Embryos were fixed in $4 \%$ paraformaldehyde for 1 day at $4{ }^{\circ} \mathrm{C}$ and then dehydrated with a graded ethanol series up to $100 \%$. Specimens in xylene were embedded in paraffin and cut at a thickness of $6 \mu \mathrm{m}$. Histological hematoxylin-eosin (H\&E) staining was carried out using standard protocols.

\section{Microinjection of mRNA and morpholino oligonucleotides} Synthetic capped mRNAs for human CUG2, zebrafish cug2, and cug2-GFP were transcribed in vitro by using the SP6 mMESSAGE mMACHINE Kit (Ambion). The synthesized mRNAs were dissolved in $0.2 \%$ Phenol Red as a tracking dye, and then microinjected into one to two cell stage embryos with $100 \mathrm{pg}$ per embryo. Morpholinos were resuspended in $1 \times$ Danieau's buffer (58 $\mathrm{mM} \mathrm{NaCl}, 0.7 \mathrm{mM} \mathrm{KCl}, 0.4 \mathrm{mM} \mathrm{MgSO}{ }_{4}, 0.6 \mathrm{mM} \mathrm{Ca}$ $\left(\mathrm{NO}_{3}\right)_{2}, 5.0 \mathrm{mM}$ HEPES, pH 7.6) with $0.1 \%$ phenol red and microinjected into embryos at the 1-4 cell stage. Concentration of morpholinos injected into embryos as follows: cug2 translation blocker, $500 \mathrm{pg} / \mathrm{embryo}$; cug2 splicing blocker, control MO, and p53 MO, 2 ng/ embryo. Injected embryos were incubated until the indicated stage and analyzed by in situ hybridization or immunostaining.

\section{DNA oligonucleotide and $\mathrm{MO}$ sequences}

The RT-PCR primers used for cloning zebrafish cug2 cDNA from a 24 hpf zebrafish cDNA library were 5'ataaaacgcctttcacgccgccaa-3' (forward) and 5'-gggctagatactgtccatcatcca-3' (reverse). The PCR primers for constructing cug2-GFP reporter were 5'- cgccatggggat gtcgtcagtaatctct-3' (forward) and 5'- cgccatggactgagtgtgtgtgtgtgca-3' (reverse). Morpholino antisense oligonucleotides for cug2 translation start site; 5' - CTG CTC TCG GTG CTT TCT TCG ACA T-3', the exon 1 splice donor site; 5'-GAA CCT TCT TCA ACT CAC CAT CAA G-3', standard control MO, 5'- CCT CTT ACC TCA GTT ACA ATT TAT A-3', p53 MO, 5'- TTG ATT TTG CCG ACC TCC TCT CCA C were designed to have no predicted internal hairpins, avoiding the presence of four consecutive $\mathrm{G}$ nucleotides, and synthesized by Gene-Tools, LLC (Corvallis, OR, USA).

\section{Additional material}

\section{Additional file 1: Phenotypes of cug2 translation blocking} morpholino (ATG-MO) in zebrafish embryos. A, B. cug2 MO-injected embryo (B) shows developmental defects including flat head, pinched midbrain-hindbrain boundary (arrowhead), thin yolk extension (arrow), and curved-up body. C, D. The translation blocking MO (ATG-MO) specifically inhibits the translation of cug2-GFP mRNA containing its targeting region. E, F. DIC image of PTU-treated cug2 morphant. The cug2 morphant shows retina degeneration and pinched brain structure (arrow) at 3 dpf. ov, otic vesicle; ret, retina. Scale bars $=200 \mu \mathrm{m}$.

Additional file 2: Early neurogenesis in cug2 morphant embryos. A, $\mathbf{A}^{\prime}$. neurogenin 1 (ngn 1) expression in control MO- (A) and cug2 MOinjected $\left(\mathbf{A}^{\prime}\right)$ embryos at the 3-somite stage (3 ss). The number of ngn 1positive neuronal precursors is increased at neural plate in cug2 MOinjected embryos $(80 \% / n=20)$. B, $\mathbf{B}^{\prime}$. Expression of deltaA $(d / A)$ in control MO- (B) and cug2 MO-injected ( $\mathbf{B}^{\prime}$ ) embryos at 3 ss. cug2 MO-injected embryos show increase of delta A-expressing neuronal precursor $(70 \% / \mathrm{n}$ $=20)$. C, $\mathbf{C}^{\prime}$. huC expression in control MO- (C) and cug2 MO-injected $\left(\mathbf{C}^{\prime}\right)$ embryos at $3 \mathrm{ss}$. The number of huC-positive differentiating neurons is decreased in cug2 MO-injected embryos $(77 \% / \mathrm{n}=26)$. D-F'. At the 20 somite stage (20 ss), ngni, deltaA, and huC expression in control MO- (D, $\mathbf{E}, \mathbf{F})$ and cug2 MO-injected embryos $\left(\mathbf{D}^{\prime}, \mathbf{E}^{\prime}, \mathbf{F}^{\prime}\right)$. During secondary neurogenesis (20 somite-stage), both neuronal precursors (ngn 1, delta A) and differentiating neurons (huC) are decreased in cug2 MO-injected embryos. G, G'. Dorsal view at $24 \mathrm{hpf}$. The number of huC-positive differentiating neurons is dramatically decreased in cug2 morphants ( $\left.\mathbf{G}^{\prime}\right)$. H. Quantification of delta A, ngn 1, and huC-positive cells in control and cug2 MO-injected embryos at 3-somite stage in the area indicated in A$C^{\prime}(n=10)$.

Additional file 3: Subcellular localization of Cug2-GFP in zebrafish embryos. Cug2-GFP protein (A) is co-localized with chromatin (B). Mitotic chromosomes are indicated by arrows (C). Scale bar $=30 \mu \mathrm{m}$.

\section{Acknowledgements and Funding}

This work was supported by the National R\&D Program for Cancer Control, Ministry for Health and Welfare (1020090) and the Basic Science Research Program (NRF-20100005431) of the National Research Foundation funded by the Korean Government (to S.L.)

\section{Author details}

'Department of Biology, Chungnam National University, Daejeon, South Korea. ${ }^{2}$ Department of Microbiology, Chungnam National University, Daejeon, South Korea. ${ }^{3}$ Genome Research Center, Korea Research Institute of Bioscience and Biotechnology, Daejeon, 305-764, South-Korea. ${ }^{4}$ Biomedical Sciences, St. George's Medical School, University of London, London, SW17 ORE, UK.

\section{Authors' contributions}

HTK, JHS, SHJ and WK carried out experiments. HTK, NSK, SL and CHK performed data analysis and participated in the design of the study. HTK, SHK, DGA, SL and CHK drafted the manuscript. SL and CHK conceived the study, participated in overall direction of the study. All authors read and approved the final manuscript.

Received: 3 May 2011 Accepted: 15 August 2011

Published: 15 August 2011

\section{References}

1. Lee S, Gang J, Jeon SB, Choo SH, Lee B, Kim YG, Lee YS, Jung J, Song SY, Koh SS: Molecular cloning and functional analysis of a novel oncogene, cancerupregulated gene 2 (CUG2). Biochem Biophys Res Commun 2007, 360(3):633-9.

2. Hori T, Amano M, Suzuki A, Backer CB, Welburn JP, Dong Y, McEwen BF, Shang WH, Suzuki E, Okawa K, Cheeseman IM, Fukagawa T: CCAN makes multiple contacts with centromeric DNA to provide distinct pathways to the outer kinetochore. Cell 2008, 135(6):1039-52.

3. Kim H, Lee M, Lee S, Park B, Koh W, Lee DJ, Lim DS, Lee S: Cancerupregulated gene 2 (CUG2), a new component of centromere complex, is required for kinetochore function. Mol Cells 2009, 27(6):697-701.

4. Gonçalves Dos Santos Silva A, Sarkar R, Harizanova J, Guffei A, Mowat M, Garini Y, Mai S: Centromeres in cell division, evolution, nuclear organization and disease. J Cell Biochem 2008, 104(6):2040-58.

5. Foltz DR, Jansen $L E$, Black BE, Bailey AO, Yates JR, Cleveland DW: The human CENP-A centromeric nucleosome-associated complex. Nat Cell Biol 2006, 8(5):458-69. 
6. Przewloka MR, Glover DM: The kinetochore and the centromere: a working long distance relationship. Annu Rev Genet 2009, 43:439-65.

7. The Synteny Database. [http://teleost.cs.uoregon.edu/synteny_db/].

8. Robu ME, Larson JD, Nasevicius A, Beiraghi S, Brenner C, Farber SA, Ekker SC: p53 activation by knockdown technologies. PLOS Genet 2007 3(5):e78.

9. Kishi S, Bayliss PE, Uchiyama J, Koshimizu E, Qi J, Nanjappa P, Imamura S, Islam A, Neuberg D, Amsterdam A, Roberts TM: The identification of zebrafish mutants showing alterations in senescence-associated biomarkers. PLOS Genet 2008, 4(8):e1000152

10. Abdelilah S, Mountcastle-Shah E, Harvey M, Solnica-Krezel L, Schier AF, Stemple DL, Malicki J, Neuhauss SC, Zwartkruis F, Stainier DY, Rangini Z, Driever W: Mutations affecting neural survival in the zebrafish Danio rerio. Development 1996, 123:217-27.

11. Furutani-Seiki M, Jiang YJ, Brand M, Heisenberg CP, Houart C, Beuchle D, van Eeden FJ, Granato M, Haffter P, Hammerschmidt M, Kane DA, Kelsh RN, Mullins MC, Odenthal J, Nüsslein-Volhard C: Neural degeneration mutants in the zebrafish, Danio rerio. Development 1996, 123:229-39.

12. Malicki J, Neuhauss SC, Schier AF, Solnica-Krezel L, Stemple DL, Stainier DY, Abdelilah S, Zwartkruis F, Rangini Z, Driever W: Mutations affecting development of the zebrafish retina. Development 1996, 123:263-73.

13. Park HC, Kim CH, Bae YK, Yeo SY, Kim SH, Hong SK, Shin J, Yoo KW, Hibi M, Hirano T, Miki N, Chitnis AB, Huh TL: Analysis of upstream elements in the $\mathrm{HuC}$ promoter leads to the establishment of transgenic zebrafish with fluorescent neurons. Dev Biol 2000, 227(2):279-93.

14. Fadool JM, Dowling JE: Zebrafish: a model system for the study of eye genetics. Prog Retin Eye Res 2008, 27(1):89-110

15. Hendzel MJ, Wei Y, Mancini MA, Van Hooser A, Ranalli T, Brinkley BR, BazettJones DP, Allis CD: Mitosis-specific phosphorylation of histone $\mathrm{H} 3$ initiates primarily within pericentromeric heterochromatin during $\mathrm{G} 2$ and spreads in an ordered fashion coincident with mitotic chromosome condensation. Chromosoma 1997, 106(6):348-60.

16. Howman EV, Fowler KJ, Newson AJ, Redward S, MacDonald AC, Kalitsis P, Choo $\mathrm{KH}$ : Early disruption of centromeric chromatin organization in centromere protein A (Cenpa) null mice. Proc Natl Acad Sci USA 2000, 97(3):1148-53.

17. Kalitsis P, Fowler KJ, Earle E, Hill J, Choo KH: Targeted disruption of mouse centromere protein $\mathrm{C}$ gene leads to mitotic disarray and early embryo death. Proc Natl Acad Sci USA 1998, 95(3):1136-41.

18. Putkey FR, Cramer T, Morphew MK, Silk AD, Johnson RS, Mclntosh JR, Cleveland DW: Unstable kinetochore-microtubule capture and chromosomal instability following deletion of CENP-E. Dev Cell 2002, 3(3):351-65.

19. Amsterdam A, Nissen RM, Sun Z, Swindell EC, Farrington S, Hopkins N: Identification of 315 genes essential for early zebrafish development. Proc Natl Acad Sci USA 2004, 101(35):12792-7.

20. Morris LG, Veeriah S, Chan TA: Genetic determinants at the interface of cancer and neurodegenerative disease. Oncogene 2010, 29(24):3453-64.

21. Kim CH, Bae YK, Yamanaka Y, Yamashita S, Shimizu T, Fujii R, Park HC Yeo SY, Huh TL, Hibi M, Hirano T: Overexpression of neurogenin induces ectopic expression of HuC in zebrafish. Neurosci Lett 1997, 239(2-3):113-6.

22. Kim CH, Ueshima E, Muraoka O, Tanaka H, Yeo SY, Huh TL, Miki N: Zebrafish elav/HuC homologue as a very early neuronal marker. Neurosci Lett 1996, 216(2):109-12.

23. Haddon C, Smithers L, Schneider-Maunoury S, Coche T, Henrique D, Lewis J: Multiple delta genes and lateral inhibition in zebrafish primary neurogenesis. Development 1998, 125(3):359-70.

24. Kim HT, Kim EH, Yoo KW, Lee MS, Choi JH, Park HC, Yeo SY, Lee DS, Kim CH: Isolation and expression analysis of Alzheimer's disease-related gene xb51 in zebrafish. Dev Dyn 2008, 237(12):3921-6.

doi:10.1186/1471-213X-11-49

Cite this article as: Kim et al: Cug2 is essential for normal mitotic control and CNS development in zebrafish. BMC Developmental Biology 2011 11:49

\section{Submit your next manuscript to BioMed Central and take full advantage of:}

- Convenient online submission

- Thorough peer review

- No space constraints or color figure charges

- Immediate publication on acceptance

- Inclusion in PubMed, CAS, Scopus and Google Scholar

- Research which is freely available for redistribution

Submit your manuscript at www.biomedcentral.com/submit
Biomed Central 